\title{
Challenges, Educational Opportunities and Barriers Faced by E.R. Board Residents During Previous Hajj Rotations
}

\author{
Ahmed Ali Shammah ${ }^{1}$ \\ ${ }^{1}$ Department of Clinical Technology, Faculty of Applied Medical Science, EMS, Umm Al-Qura University, KSA \\ Correspondence: Dr. Ahmed Ali Shammah, Department of Clinical Technology, Faculty of Applied Medical \\ Science, EMS, Umm Al-Qura University, KSA.
}

Received: September 28, 2017 Accepted: May 22, 2018 Online Published: June 11, 2018

doi:10.5539/gjhs.v10n7p122 URL: https://doi.org/10.5539/gjhs.v10n7p122

\begin{abstract}
Objectives: The prominence of using preventive health measures allowed medical residents to enhance the awareness about barriers and challenges during Hajj pilgrimage. Hajj pilgrimage usually comprises of assorted risk factors and infections that reveal the paucity of intervention programs. The study aims to examine the challenges, educational opportunities, and barriers experienced by emergency residents during Hajj rotations.

Design Setting: The study has employed cross-sectional and quantitative approach to examine the challenges and educational awareness among emergency residents in Makkah, Saudi Arabia in the year 2015. Subjects: Participants were asked about the best recommended factors. Main Outcome Measure: Statistical package for social sciences (SPSS) was used to analyse the data. Frequencies were selected to analyse the obtained responses

Results: Findings have asserted mixed responses toward the challenges and educational awareness among medical residents. $80 \%$ of the respondents possessed highest level of training to meet the educational goals. Moreover, majority of the residents have also stated that they were keen to start Hajj rotation. Negative responses were indicated for objectives and clinical duties by $76 \%$ residents. Responses about patients' volume and varieties were shown positively by $83 \%$ residents.
\end{abstract}

Conclusion: Saudi government should focus on these challenges and barriers to enhance the assurance level of educational programs among emergency residents.

Keywords: barriers, challenges, educational opportunities, Hajj Rotation, residents

\section{Introduction}

Hajj is a unique event, which requires different researches and planers to meet the standard requirement for maintaining healthy gathering related to standard medical management. There are substantial prospects to enhance awareness among Hajj pilgrims about the prominence of using preventive health measures (Alqahtani, Wiley, Tashani, Willaby, Heywood, BinDhim, \& Rashid, 2016). Barriers and challenges, concerning the religious tourism of Hajj and Umrah in Saudi Arabia, are needed to be recognized. There is an imperative requirement of structured portfolio for every specialty. Therefore, it is a great area of improvement in the outcome of training with any planned effort prior to Hajj that has a major impact on Pilgrims' health. There are many health risk factors, concerning the disasters during Hajj according to early years, which made the management alert to predict the adverse situation and control them (Alotaibi, 2016).

Management of Hajj is an irresistible task; and due to this, an international association is required to be implemented for multilateral planning. It is not merely helpful for the health aspect, but also for the assimilation of Muslims satisfaction. Therefore, the study has aimed to evaluate the benefits of Hajj Rotation in the six competencies of Emergency Medical Residents, which include patient care, medical knowledge, practice-based learning and improvement, interpersonal and communication skills, professionalism and health system based practice (Pilgrims Health). The study targets to explore the barriers and challenges, needed to be solved to develop and maintain a structured portfolio for human resources and a better organized working environment.

\subsection{Challenges Faced by Emergency Medical Residents}

Emergency medical residents faced a significant number of challenges during Hajj rotation due to mass gathering. It has been evaluated that such challenges may also result in the development of severe complications among the 
citizens of different countries, who visit for pilgrimage. Shujaa \& Alhamid (2015) have carried out a comprehensive investigation about the challenges, that may develop during Hajj. The study revealed that infection disease has always been a major threat during Hajj; especially with the citizens of poor or low-income countries and crowded accommodations. It has been further evaluated that extreme heat, poor hygiene, poorly prepared and stored food, unknown medical background, and inadequate pre-Hajj vaccination may also result in the spread of infectious diseases. Some of the common infectious diseases mainly include meningitis, food/water borne diseases, respiratory/airborne diseases, and blood borne diseases. The Ministry of Health, Saudi Arabia, mainly recognize such threats in the initial days of Hajj by taking a number of infectious control measures. It is a fact that the emergency medical residents are mostly involved in providing idealistic healthcare to the pilgrims during Hajj rotations. The health issues, including the communicable and non-communicable diseases, are encountered during the Hajj. However, an accurate conclusion could not be made due to poor exploration in this area. There is an effective educational opportunity for all medical specialists to get benefits from the Hajj season. However, diverse nature of infections have become a major challenge for the emergency medical residents as most of them also get affected from such infections while performing their duties.

Boker (Boker, 2016) has also described the crucial role of medical residents, during Hajj. The study has mentioned that certain remarkable advancements have been developed by the healthcare providers during Hajj seasons in this decade. Moreover, the Saudi government has also allocated a significant number of facilities, logistics, and personnel to assure the safety of pilgrims. The study has observed that the recruited residents were not highly satisfied with direct observation along with the feedbacks. Furthermore, it has also shown that communication is the most serious challenge for the residents during pilgrimage. Language barrier is the most common challenge faced by the residents while communication with individuals from different countries. At the same time, difficulty in reaching patients because of massive crowd is another challenge for the residents. However, these challenges have negatively affected the performance of medical residents. At the same time, most of the residents overcome such challenges through their educational competencies.

\subsection{Educational Opportunities During Pilgrimage for Residents}

Leggio et al. (Leggio, Mobrad, Alessandro, Krtek, Alrazeeni, Sami, \& Raynovich, 2016) has thoroughly discussed the experience of emergency medical service providers. The study identified that the Hajj pilgrimage has a direct relevance with various educational opportunities for the residents to learn about the emergency situations. Most of the participants agreed on the statement regarding the association between educational opportunities along with pilgrimage. The participants showed their experiences as beneficial and honorable for the Emergency Medical Service (EMS) education. Moreover, participants have also encountered different medical and trauma patients, which provided them with diverse opportunities to apply the Emergency Medical Service (EMS) knowledge and medical skills during emergency situations. The study further elaborated, that most of the recruited residents reported an increased confidence level, motivation, and ability to think critically for the survival of different patients. Thus, attending the Hajj mass gathering was significantly helpful for the emergency medical residents to enhance their educational level and skill set in an effective way.

\subsection{Barriers Faced by Residents During Hajj Pilgrimage}

Along with the challenges and educational opportunities, the medical residents also faced a significant number of barriers during Hajj pilgrimage. The most common barrier, faced by the residents, was language barrier. The main reason is that people from diverse linguistic backgrounds, visit Makkah and Medina during Hajj pilgrimage. Therefore, language barrier and communication problems are severely occurred for the emergency medical residents. Almasabi (Almasabi, 2013) has revealed that healthcare services play a major role in the Hajj pilgrimage. Thus, most of the emergency medical residents are usually deployed to perform their responsibilities for better learning. Language barrier usually affects the normal process of investigation, carried out by emergency medical residents. The study has further elaborated that managing an occasion, in which millions of people gather, needs proper planning by the ministries to ensure sufficient transportation, accommodation, and healthcare facilities. Most commonly, healthcare service demand is extremely high during Hajj, which is identified as another barrier for the medical residents. At the same time, reaching to the patients is another barrier because of mass gathering during Hajj pilgrimage.

\section{Materials and Methods}

The study has employed cross-sectional approach, and interviews have been conducted with the groups of residents, who worked during Hajj pilgrimage in Makkah, Saudi Arabia in the year 2015. The research was continued till the measurable factors were obtained as the best indicators for the educational procedure. It is also indicated that the best recommended solution can eradicate the main barriers. The factors were reviewed and 
validated by medical education professors as the data collection form was finalized by them. The data was obtained from almost all the residents, who worked during Hajj from 1424-1429H. The data was collected from Riyadh Center only, and was analyzed using the Statistical Package of Social Sciences (SPSS). Data, collected from Jeddah Center, was analyzed for scientific comparison. The study was limited with the exclusion of Jeddah Center and Last Hajj Rotation.

\section{Results}

The researcher repetitively interviewed groups of residents, who worked during Hajj in Makah; till common 32 measurable factors were identified. Those factors were the best indicators for the educational process, the real barriers, and the best recommended possible solutions. The 32 factors were reviewed and validated by medical education professors, then a collection of data form was finalized. It has been evaluated through demographics that only 2 female respondents participated in the study out of 30 participants; whereas, 28 male participants were recruited as participants in the study (Table 1).

Table 1. Gender based distribution of Participants

\begin{tabular}{lll}
\hline & N & \% \\
\hline Male & 28 & 93.33 \\
Female & 2 & 6.67 \\
\hline
\end{tabular}

Quantitative evaluations for the study have shown mixed responses for the factors examined during Hajj rotation. Table 2 has represented the level of training for the respondents included in the study. From the above findings, it has been examined that level of training R3 and R4 occupied greater extent mutually (40\%). It shows the awareness of training among respondents during Hajj rotations.

Table 2. Level of Training

\begin{tabular}{lll}
\hline & Number of Participants & \% \\
\hline R1 & 3 & 10 \\
R2 & 3 & 10 \\
R3 & 12 & 40 \\
R4 & 12 & 40 \\
\hline
\end{tabular}

Respondents were asked questions about the challenges and barriers during Hajj rotation. Findings for the responses are presented in Figure 1, where $80 \%$ of the participants showed positive behaviour to start the rotation during Hajj period. Whereas, none of them have shown their interest against the Hajj rotation.

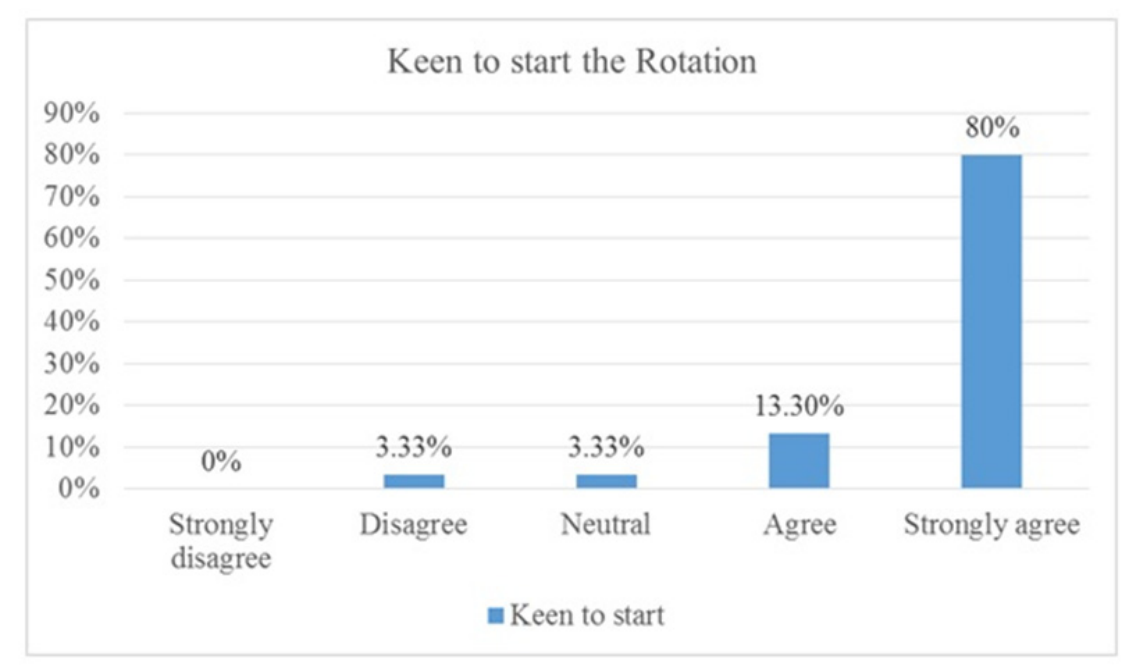

Figure 1. Keen to Start the Rotation 
Table 3 has shown the findings about objectives and clinical duties. The findings have shown negative responses regarding the objectives and clinical duties as $76 \%$ respondents asserted that clinical duties and objectives were clearly set to meet educational goals. Thereby, it is stated that there is less satisfaction about the presumed objectives and clinical duties during Hajj rotation.

Table 3. Objectives and Clinical Duties

\begin{tabular}{lll}
\hline & $\mathbf{N}$ & \% \\
\hline Strongly disagree & 23 & 76 \\
Disagree & 1 & 3.33 \\
Neutral & 2 & 6.67 \\
Agree & 2 & 6.67 \\
Strongly agree & 2 & 6.67 \\
\hline
\end{tabular}

Table 4 has shown the findings about patient volume and varieties. The findings have shown positive responses regarding the patient volume and varieties as $83 \%$ respondents asserted that patient volume and varieties were sufficient to meet educational goals. Thereby, it is stated that the respondents were highly satisfied with the awareness provided for the patient volume and varieties during Hajj rotation.

Table 4. Patient Volume and Varieties

\begin{tabular}{lll}
\hline & N & \% \\
\hline Strongly disagree & 0 & 0 \\
Disagree & 1 & 3.33 \\
Neutral & 2 & 6.67 \\
Agree & 2 & 6.67 \\
Strongly agree & 25 & 83 \\
\hline
\end{tabular}

Figure 2 has shown the results about environmental and organizational problems. The results provided mixed responses regarding the environmental and organizational problems as $30 \%$ respondents $(n=9)$ asserted, that environmental and organizational problems were resolved to meet educational goals. However, $40 \%$ respondents $(n=12)$ stated that environmental and organizational problems were not resolved to meet educational goals. Thereby, it is examined that the respondents were not much satisfied with the solutions provided for resolving the environmental and organizational problems during Hajj rotation.

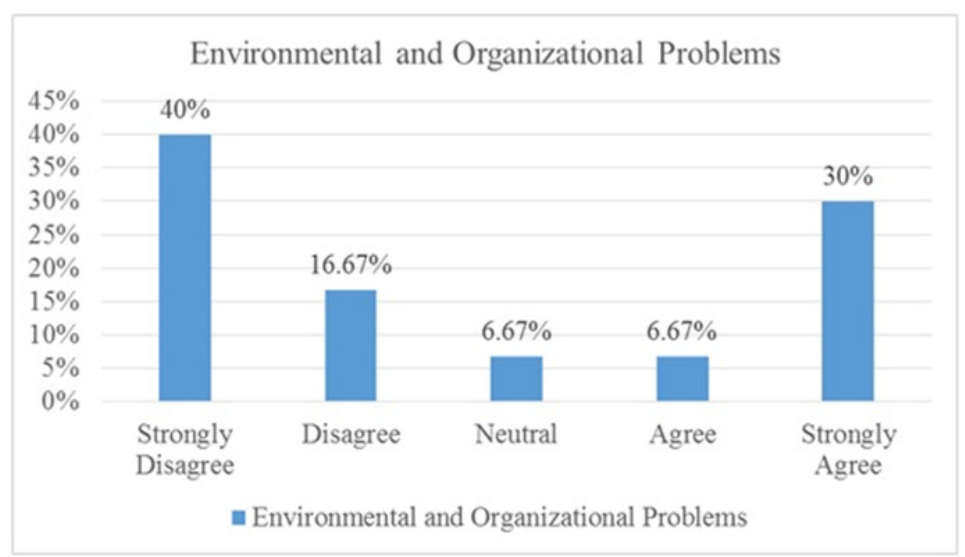

Figure 2. Environmental and Organizational Problems 


\section{Discussion}

The results are based on the statistical analysis of the data collected from residents, who worked during Hajj. The results showed that there were significant differences on the basis of gender, but not on the basis of training. The residents were observed keenly to start the rotation and were recommended to continue. The patients' volume and variety of cases were sufficient to meet the best educational goals. The health issues, including the communicable and non-communicable diseases, were encountered during Hajj pilgrimage. However, an accurate conclusion could not be made because of the poor exploration in this area. The findings demonstrated that there are specific health issues that occurred during Hajj (Al Masud, Bakar, \& Yussof, 2016). Moreover, there is an effective educational opportunity for all medical specialties to get benefits from the Hajj season.

The transmission of infectious diseases is likely to increase in mass gathering like Hajj pilgrimage in Saudi Arabia (Alqahtani, Alfelali, Arbon, Booy, \& Rashid, 2015). A study revealed that the most common disease that is likely to affect most of the pilgrims is acute respiratory infection. The main reasons for the transmission of this disease are air pollution, intense congestion, compromised hygiene, and sharing of accommodation (Alqahtani, et al., 2015; Al-Tawfiq, Zumla, \& Memish, 2013). The Hajj pilgrimage is presented as a public health challenge for the government of Saudi Arabia. The government needs to manage a huge number of pilgrims and generate appropriate response to emerging infections during Hajj pilgrimage (Al-Tawfiq, Zumla, \& Memish, 2014; Sridhar, Brouqui, Parola, \& Gautret, 2015). A study also revealed that the increased variation in hygiene, vaccine uptake, protective measures, and compliance among the pilgrims resulted in increased transmission of infectious diseases.

The Hajj pilgrimage has significant educational opportunity for the Emergency Medical Service (EMS) students. The students are specifically recommended about improving the educational experience, and the recommendations render practical benefits for the organization of mass gatherings (Leggio et al., 2016). The unhealthy and elderly people can suffer physical stress while performing Hajj rituals, which may result in cardiac ischemia. The cardiovascular complications are considered as the common cause of hospitalization and death during Hajj pilgrimage (Shafi, Booy, Haworth, Rashid, \& Memish, 2008; D'Alessandro, Leggio, \& Al, 2013). However, the retrieving of cardiac arrest patients from a massive crowd is quite dangerous and difficult to manage. A stud revealed that improved education, water supplies, and hygienic conditions are associated with decreased number of patients, suffering gastroenteritis. Hajj offers various opportunities to the pilgrims for the development of decision-making skills, which increase their ability of critical thinking as they find themselves making decisions regarding patient care. The repeated performance of basic assessment skills; like vital signs, have helped in the development of proficiency, which provided the pilgrims with better experience.

\section{Conclusion}

The educational opportunities were offered to the pilgrims before attending the mass gathering to perform Hajj. The mixed responses were obtained from the Hajj emergency residents. From the analysis, it has been examined that these emergency residents possessed highest level of training; whereas, most of the residents were graduates. There were certain challenges, experienced by emergency medical residents that create severe complications during the Hajj rotation. Infection is identified as the major threat, examined by residents during Hajj rotation. Communicable and non-communicable diseases were further indicated by the respondents. However, the assurance of Hajj pilgrims is provided by the Saudi government that allocates facilities, personnel, and logistics. Moreover, language barrier was also emphasized as the most common challenge, experienced by residents. The gap exists between the medical residents because language restricts them to communicate with each other. Thereby, medical residents usually utilize their skills and abilities to perform their responsibilities for better learning. Emergency situations were well-comprehended by Hajj pilgrims with the assistance of emergency residents. The level of status about educational awareness did not receive much attention among respondents. Although, attending Hajj pilgrimage is a significant gathering, there was no awareness provided by the Saudi government to medical residents to enhance their educational level.

\section{Acknowledgements}

The author is very thankful to all the associated personnel in any reference that contributed in/for the purpose of this research.

\section{Competing Interests Statement}

The research has no conflict of interest and is not funded through any source.

\section{References}

Al Masud, S. M. R., Bakar, A. A., \& Yussof, S. (2016). Determining the Types of Diseases and Emergency Issues 
in Pilgrims During Hajj: A Literature Review. International Journal of Advanced Computer Science \& Applications, 1, 86-94. https://doi.org/10.14569/IJACSA.2016.071011

Almasabi, M. H. (2013). Factors influence and impact of the implementation of quality of care in Saudi Arabia. Journal of Medicine and Medical Sciences, 4, 92-5.

Alotaibi, H. (2016). Strategic Practices and Development of the Hotel Sector for Pilgrims in Makkah and Madinah. The International Journal of Business \& Management, 4, 309.

Alqahtani, A. S., Alfelali, M., Arbon, P., Booy, R., \& Rashid, H. (2015). Burden of vaccine preventable diseases at large events. Vaccine, 33, 6552-63. https://doi.org/10.1016/j.vaccine.2015.09.076

Alqahtani, A. S., Wiley, K. E., Tashani, M., Willaby, H. W., Heywood, A. E., BinDhim, N. F., \& Rashid, H. (2016). Exploring barriers to and facilitators of preventive measures against infectious diseases among Australian Hajj pilgrims: cross-sectional studies before and after Hajj. International Journal of Infectious Diseases, 47, 53-59. https://doi.org/10.1016/j.ijid.2016.02.005

Al-Tawfiq, J. A., Zumla, A., \& Memish, Z. A. (2013). Respiratory tract infections during the annual Hajj: potential risks and mitigation strategies. Curr Opin Pulm Med., 19, $192-97$. https://doi.org/10.1097/MCP.0b013e32835flae8

Al-Tawfiq, J. A., Zumla, A., \& Memish, Z. A. (2014). Travel implications of emerging coronaviruses: SARS and MERS-CoV. Travel medicine and infectious disease, 12, 422-28. https://doi.org/10.1016/j.tmaid.2014.06.007

Boker, A. M. (2016). Clinical exposure and organization of the Critical Care rotation during the Hajj periods in 1434-1435; perspectives of Arabian Saudi Anesthesiology Program Residents.

D'Alessandro, K., Leggio, J. W., \& Al, H. M. (2013). World's largest gathering. Muslim mass pilgrimage poses EMS logistical \& planning challenges. JEMS: a journal of emergency medical services, 38(9), 52-57.

Leggio, W. J., Mobrad, A. D., Alessandro, K. J., Krtek, M. G., Alrazeeni, D. M., Sami, M. A., \& Raynovich, W. (2016). Experiencing emergency medical services at Hajj. Australasian Journal of Paramedicine, 13.

Shafi, S., Booy, R., Haworth, E., Rashid, H., \& Memish, Z. A. (2008). Hajj: health lessons for mass gatherings. Journal of Infection and Public Health, 1, 27-32. https://doi.org/10.1016/j.jiph.2008.08.008

Shujaa, A., \& Alhamid, S. (2015). Health response to Hajj mass gathering from emergency perspective, narrative review. Turkish journal of emergency medicine, 15, 172-76. https://doi.org/10.1016/j.tjem.2015.02.001

Sridhar, S., Brouqui, P., Parola, P., \& Gautret, P. (2015). Imported cases of Middle East respiratory syndrome: an update. Travel medicine and infectious disease, 13, 106. https://doi.org/10.1016/j.tmaid.2014.11.006

\section{Copyrights}

Copyright for this article is retained by the author(s), with first publication rights granted to the journal.

This is an open-access article distributed under the terms and conditions of the Creative Commons Attribution license (http://creativecommons.org/licenses/by/4.0/). 